\title{
Phenotypic Plasticity for Growth and Nutrient Uptake in Milk Thistle under Salt Stress: Modulatory Role of Soil Supplementations with Plant Growth Promoters
}

\author{
Noreen Zahra $^{1^{*}}$, Abdul Wahid ${ }^{1 *}$, Shahzad Maqsood Ahmad Basra ${ }^{2}$ and Muhammad Arfan ${ }^{1}$ \\ ${ }^{1}$ Department of Botany, University of Agriculture, Faisalabad 38040, Pakistan \\ ${ }^{2}$ Department of Agronomy, University of Agriculture, Faisalabad 38040, Pakistan \\ *For correspondence: noreenzahra59@gmail.com; drawahid@uaf.edu.pk \\ Received 19 November 2020; Accepted 28 December 2020; Published 25 January 2021
}

\begin{abstract}
Salinity stress negatively affects key physiological phenomena in plants while plants show great variability and respond differentially for tolerance to salt stress. Usually, nutrients imbalances affect specific plant tissues and physiological processes which are requisite for normal plant growth and development. The aim of this two-year (2017 and 2018) simulated field study was to investigate phenotypic plasticity for growth, relative leaf water content (RLWC) and nutrient status in milk thistle [Silybum marianum (L.) Gaertn.] ecotypes and the potential role of soil supplementation with pre-optimized levels of plant growth promoters (PGPs) in modulating these attributes under control and salinity (12 dS/m) stress. Four ecotypes of milk thistle were collected from three ecologically distinct zones including Faisalabad (FSD) and Kalar Kahar (KK) - semi-arid zone, Gujranwala (GUJ) - hot semi-arid zone and Quetta (QTA) - cool semi-arid zone. The studied nutrients were nitrate-N, phosphate-P, sulfate-S, sodium $(\mathrm{Na})$, potassium $(\mathrm{K})$ and calcium $(\mathrm{Ca})$. The soil supplemented PGPs, applied with irrigation water, were ascorbic acid (AsA), thiourea (TU) and moringa leaf extract (MLE) at $250 \mu \mathrm{M}, 500 \mu \mathrm{M}$ and $3 \%$, respectively of soil moisture content at field capacity. Results indicated that soil supplementation of PGPs in the field conditions is a feasible approach for enhancing nutrient uptake of milk thistle ecotypes under salt stress, while the effect of salinity stress restricted the uptake of the studied nutrients and caused their imbalance. Although the salinity stress reduced shoot and root dry matter, RLWC and restricted the uptake of these nutrients irrespective of ecotypes, the levels of nitrate-N, phosphate-P, K, sulfate-S, $\mathrm{Ca}$, and RWC contents increased more with the soil supplementation of AsA followed by MLE as compared to other soil supplements in both the study years. Among the ecotypes, QTA followed by KK and FSD ecotypes gained more dry weight with greater leaf RWC and higher tissue nutrient contents due to PGPs under salt stress. The principal component analysis and correlation data revealed the existence of distinct phenotypic plasticity in the milk thistle ecotypes for nutrient acquisition with soil supplementation of PGPs under salinity stress. To conclude, ecotypes from QTA and KK were more promising than the others while AsA and MLE were better soil supplements in improving shoot and root nutrients under salt stress. (C) 2021 Friends Science Publishers
\end{abstract}

Keywords: Plant growth promoters; Salinity; Nutrients; Phenotypic plasticity; Milk thistle

\section{Introduction}

Salt stress reduces plant growth and development due to water deficit, ionic imbalance and ionic toxicity (Munns and Tester 2008; Lin et al. 2017; Zahra et al. 2018), and nutrient deficiencies of various macro- and micro-nutrients (Niste et al. 2014). These nutrients are a prerequisite for essential physiological processes like the synthesis of macromolecules, enzymes activation, stomatal regulation and osmotic homeostasis (Fageria and Moreira 2011; Shahid et al. 2020). Reduction in relative water content (RWC), photosynthesis and dry matter yield is a common effect of salinity stress (Polash et al. 2018; Saddiq et al. 2019). Ionic toxicity due to $\mathrm{Na}^{+}$and $\mathrm{Cl}^{-}$reduces the uptake of other nutrients and causes metabolic disturbances (Munns 2002). It is notable that nutrient uptake varied widely in the milk thistle ecotypes collected from broad range of geographical areas in the western USA for selenium uptake and soil characteristics (Feist and Parker 2001). Other studies showed the existence of genetic diversity for nutrient uptake in alfalfa under salt stress (Benabderrahim et al. 2020; Bhattarai et al. 2020).

Plant growth promoters (PGPs) modulate plant responses to biotic and abiotic stresses and regulate their growth and developmental cascades (Zahra et al. 2020). Different approaches have been beneficial in ameliorating salt affected soils including physical, biological, and 
amending soil properties with organic and inorganic chemicals (Ansari et al. 2019; Niamat et al. 2019). There are some important chemical growth promoters that have been used in different ways including, seed pretreatment, foliar spray and medium supplementation. For instance, thiourea (TU) is a synthetic compound, which contains sulfur (as $\mathrm{SH}$ ) and nitrogen (as - NH2) functional groups in its structure (https://byjus.com/chemistry/thiourea/). It is an important PGP, which influences several plant growth-related processes under different abiotic stress factors (Wahid et al. 2017). Exogenous application of TU significantly improved the achene yield and nutrient status ( $\mathrm{N}, \mathrm{P}$, and $\mathrm{K}$ ) and maintained higher nitrate reductase activities in sunflower crop (Akladious et al. 2014). Ascorbic acid (AsA), a PGP and an antioxidant, was implicated in the promotion of plant growth and development, and in improving anti-oxidative defense by participating in phytohormone-mediated signaling networks under different abiotic stresses (Akram et al. 2017). AsA also alleviated salinity stress effects by reducing the uptake of toxic ions $\mathrm{Na}^{+}$and $\mathrm{Cl}^{-}$ions whilst regulating the plant metabolism by increasing the availability of water and enhancing nutrients assimilation under salt stress (Barakat 2003; Aliniaeifard et al. 2016). Moringa is a valuable miracle tree, whose leaves are enriched with vitamins, amino acids, antioxidants, and mineral nutrients. The leaf extract of moringa leaves (MLE) was used as bio-stimulant of growth. The exogenous application of MLE efficiently increased the uptake of different macronutrients $(\mathrm{N}, \mathrm{P}, \mathrm{K}$, and $\mathrm{S}$ ) and increased plant growth and development (Hoque et al. 2020) and mitigates salt-induced adversities (Merwad 2018).

Milk thistle [Silybum marianum (L.) Gaertn.] is a herbaceous plant, belonging to family Asteraceae (Omidbaigi and Nobakht 2001). The seed of milk thistle is enriched with flavonolignans such as silymarin, silybin, sliychristin, silydianin, and isosilybin (Bhattacharya 2011). Its silymarin constituent manifests excellent anti-oxidative properties and is used to cure different diseases (Lucini et al. 2016). The seeds of milk thistle are extracted for pharmaceutical industries as a common drug to protect many types of liver disorders including cirrhosis, fatty liver, viral and toxic hepatitis, and damage induced by toxic agents (Lucini et al. 2016; Bhattacharya 2011). Therefore, the cultivation demand for milk thistle is increasing worldwide (Karkanis et al. 2011; Bhattacharya 2011). But to dismay, literature shows that no coherent and systematic research has been conducted to domesticate milk thistle and produce cultivars for efficient nutrient uptake and silymarin biosynthesis under abiotic stresses. We hypothesize that the phenotypic plasticity in milk thistle may be closely linked with inherent ability of ecotypes to adapt and survive in saline areas. Moreover, soil supplementation of PGPs may limit salt stress effects and improve growth, water and tissue nutrient status. The objective of this study was to explore phenotypic plasticity for changes in growth, water and nutrient contents in different milk thistle ecotypes with soil supplementation of different selected PGPs under salinity stress.

\section{Materials and Methods}

\section{Source of milk thistle ecotypes and field simulation}

Milk thistle ecotypes were collected from Quetta (QTA; $30^{\circ} \mathrm{N}$ latitude, $66^{\circ} \mathrm{E}$ longitude and $1679 \mathrm{~m}$ above sea level); Faisalabad (FSD; $31^{\circ} \mathrm{N}$ latitude, $73^{\circ} \mathrm{E}$ longitude and $184 \mathrm{~m}$ above sea level); Gujranwala (GUJ; $58^{\circ} \mathrm{N}$ latitude, $45^{\circ} \mathrm{E}$ longitude and $231 \mathrm{~m}$ above sea level) and Kallar Kahar (KK; $46^{\circ} \mathrm{N}$ latitude; $72^{\circ} \mathrm{E}$ longitude; $554 \mathrm{~m}$ above sea level). These ecozones were commonly dissected into three ecological zones cold semi-arid (QTA), semi-arid (FSD-and $\mathrm{KK}$ ) and hot semi-arid (GUJ). After collecting the plants from their natural habitats, the ecotypes were assessed for their growth and multiplication in Faisalabad conditions.

Simulated field-plot experiments were conducted to determine the innate behavior of different milk thistle ecotypes in Faisalabad conditions for nutrient uptake, and data were evaluated for salinity tolerance in terms of different morphological and physiological responses. The plot size was $2 \mathrm{~m} \times 4 \mathrm{~m}$. Before sowing seeds, the soil was dug out to the depth of $60 \mathrm{~cm}$; the trenches lined with polythene sheets and soil refilled. The seeds of milk thistle ecotypes were sown on November $17^{\text {th }}$ in 2017 and on November $20^{\text {th }}$ in 2018 under open field conditions at 1-2 $\mathrm{cm}$ depth and $60 \mathrm{~cm}$ row spacing with a seeding rate of 100 seeds $\mathrm{m}^{-2}$. Two times weed hoeing was done manually 25 and 55 days after sowing. The salinity level (to achieve 12 $\mathrm{dS} / \mathrm{m}$ ) was developed at seedling stage by using $\mathrm{NaCl}$ salt $(99.2 \%$ pure) with three irrigation intervals. Moringa leaf extract was prepared according to Khan et al. (2017). The seedlings were assigned to 4 sub-plots with three replicates each. At BBCH principal growth stage 3 (Martinelli et al. 2015), salt stress (12 dS/m) and PGPs viz., TU (500 $\mu \mathrm{M})$, AsA $(500 \mu \mathrm{M})$, and MLE (3\%) solutions were soil supplements were applied to maintain their final concentrations at soil field capacity. The experiment was performed in randomized complete block design with three replicates. The soils from these four locations were analyzed for physicochemical properties. Faisalabad soil was more fertile due to having higher organic matter and $\mathrm{P}$ contents. The $\mathrm{K}$ was higher in QTA soils while $\mathrm{NO}_{3}{ }^{-} \mathrm{N}$ were similar in the soil from both locations. The decreasing order of electrical conductivity of soil extract (ECe) was obtained as FSD < GUJ < QTA and KK. Availabale sodium in QTA and KK soil was higher than from GUJ and FSD soil. In Faisalabad soil, the $\mathrm{Cl}^{-}$concentration was higher than the QTA soil. Besides, sodium adsorption ratio (SAR), and Ca and $\mathrm{Mg}$ were also higher in QTA and KK soil, respectively (Table 1).

\section{Plant dry matter yield}

Plants were harvested at $\mathrm{BBCH}$ principal growth stage 5 on May 17 of 2017 and May 13 in 2018. Shoot and root fresh and dry weights were measured after harvesting the plants 
Zahra et al. / Intl J Agric Biol, Vol 25, No 3, 2021

Table 1: The physico-chemical properties of soil collected from the native areas of each ecotype

\begin{tabular}{|c|c|c|c|c|c|c|c|c|c|c|}
\hline \multirow[t]{2}{*}{ Sample } & \multicolumn{2}{|c|}{$\begin{array}{c}\text { AB-DTPA Extractable } \\
(\mathrm{mg} / \mathrm{kg})\end{array}$} & & & \multirow[t]{2}{*}{$\mathrm{pH}$} & \multirow[t]{2}{*}{$\mathrm{ECe}(\mathrm{dS} / \mathrm{m})$} & \multicolumn{3}{|c|}{$\mathrm{mmol} / \mathrm{L}$} & \multirow[t]{2}{*}{ SAR } \\
\hline & $\mathrm{P}$ & $\mathrm{K}$ & Organic carbon $(\%)$ & Saturation (\%) & & & $\mathrm{Na}^{+}$ & $\mathrm{Cl}^{-}$ & $\mathrm{Ca}+\mathrm{Mg}$ & \\
\hline Faisalabad & 2.24 & 169 & 1.15 & 38.29 & 7.97 & 0.56 & 2.39 & 2 & 5.10 & 1.49 \\
\hline Faisalabad & 2.15 & 164 & 1.06 & 38.16 & 8.05 & 0.58 & 2.65 & 2 & 5.50 & 1.60 \\
\hline Gujranwala & 1.25 & 159 & 1.13 & 35.21 & 8.20 & 0.65 & 3.68 & 3 & 5.70 & 1.50 \\
\hline Gujranwala & 1.04 & 167 & 0.85 & 36.24 & 8.10 & 0.75 & 4.03 & 3 & 5.90 & 1.39 \\
\hline Quetta & 0.58 & 244 & 0.49 & 41.21 & 7.86 & 2.23 & 8.30 & 6 & 18.40 & 2.73 \\
\hline Quetta & 0.44 & 212 & 0.34 & 40.63 & 7.81 & 2.29 & 8.17 & 6 & 18.60 & 2.68 \\
\hline Kallar Kahar & 2.2 & 157 & 0.81 & 34.20 & 8.30 & 4.20 & 6.28 & 4 & 10.12 & 1.85 \\
\hline Kallar Kahar & 2.1 & 195 & 0.85 & 36.21 & 8.40 & 3.90 & 6.38 & 5 & 11.24 & 1.67 \\
\hline
\end{tabular}

(nine plants per treatment). The intact plants were carefully dug out from the soil to ensure maximum recovery of root mass; excess of soil removed, washed and blotted dry. Fresh weight of shoot and root was taken after cutting the shoot from root with a portable balance. To measure dry weight, these parts were put in paper bags, dried in an oven at $65^{\circ} \mathrm{C}$ for seven days and dry weight recorded for each treatment in triplicate.

\section{Relative leaf water content (RLWC)}

Leaves from the mature plants were collected to determine RLWC. A $0.5 \mathrm{~g}$ of fresh discs cut from fully expanded leaves $(\mathrm{FW})$ were floated in petri dishes containing distilled water under light for $4 \mathrm{~h}$. To get turgid weight (TW), the excess water was blotted away. These discs were dried for $72 \mathrm{~h}$ at $80^{\circ} \mathrm{C}$ to get dry weight (DW). The RLWC was calculated with the equation:

$$
\operatorname{RLWC}(\%)=(\text { FW-DW }) \times 100 /(\text { TW-DW })
$$

\section{Measurement of tissue nutrients}

To measure nitrate-N with the methods of Kowalenko and Lowe (1973), $0.5 \mathrm{~g}$ of dried grinded material was extracted in $5 \mathrm{~mL}$ of distilled water by boiling for $1 \mathrm{~h}$, filtered and made the volume up to $50 \mathrm{~mL}$. To $3 \mathrm{~mL}$ of the extract, $7 \mathrm{~mL}$ of working chromotropic acid solution was pipetted with a thrust and briefly vortexed. After $20 \mathrm{~min}$, the intensity of yellow colored complex was read at $430 \mathrm{~nm}$ with UV-VIS spectrophotometer (U-2001, Tokyo, Japan) using distilled water as blank. The nitrate- $\mathrm{N}$ content in the unknown samples was ascertained by preparing a standard curve $\left(10-100 \mathrm{mg} / \mathrm{L} \mathrm{NO}_{3}^{-}\right)$.

To measure phosphate- $\mathrm{P}, \mathrm{K}$ and $\mathrm{Ca}$ contents, the plant samples were digested in $2 \mathrm{~mL}$ of acid mixture $\left(\mathrm{HNO}_{3}\right.$ and $\mathrm{HClO}_{4}$ in 3:1 ratio) with the methods of Yoshida et al. (1976). To estimate phosphate-P, $1 \mathrm{~mL}$ of the extract from the above was added to $2 \mathrm{~mL}$ of the $2 \mathrm{~N} \mathrm{HNO}_{3}$ and diluted to $8 \mathrm{~mL}$. After adding $1 \mathrm{~mL}$ of molybdatevandate reagent, the final volume was made up to $10 \mathrm{~mL}$, briefly vortexed and let stand for $20 \mathrm{~min}$ at room temperature. The color intensity was measured at $420 \mathrm{~nm}$ using UV-VIS spectrophotometer (U-2001, Tokyo, Japan) using distilled water as blank.
The amount of phosphate-P was determined from the unknown samples by preparing a standard curve ( 2.5 to 15.0 $\left.\mathrm{mg} / \mathrm{L} \mathrm{PO}_{4}{ }^{3-}\right)$. The amounts of $\mathrm{K}$ and $\mathrm{Ca}$ in the samples were determined using flame photometer (Sherwood 410, UK), while standard curves were constructed by preparing graded series $(0-40 \mathrm{mg} / \mathrm{mL})$ separately for both the ions.

Tendon et al. (1993) method was used for determination of sulfur-S. Ten $\mathrm{mL}$ of extract was taken in a $50 \mathrm{~mL}$ volumetric flask and added with $1 \mathrm{~mL}$ of $6 \mathrm{~N} \mathrm{HCl}$ and $1 \mathrm{~mL}$ of $0.5 \%$ gum acacia solutions. Swirled and added $0.5 \mathrm{~g}$ barium chloride crystals and waited for $1 \mathrm{~min}$. Flasks were swirled again until the crystals were dissolved. Transmittance of the solution was taken on a UV-VIS spectrophotometer (U-2001, Tokyo, Japan) at $440 \mathrm{~nm}$. The sulfate-S in the unknown samples was estimated by preparing graded sulfate standards $(0,4,8,12,16$, and 20 $\mathrm{mg} / \mathrm{L}$ ) from 100 ppm stock solution prepared from $\mathrm{K}_{2} \mathrm{SO}_{4}$.

\section{Statistical analysis}

The data were subjected to statistical analysis using online software Statisix8.1 to find out significance of variance sources while Least Significant Difference (LSD) test was applied to compare the treatment means at 5\% level of probability. The Principal Component Analysis (PCA) was made keeping the ecotypes and nutrients as the components grown under salinity and soil supplementation. Furthermore, Pearson's correlations were drawn between dry weight and their nutrient contents of shoot and root.

\section{Results}

\section{Plant dry matter yield}

Statistical data revealed significant $(\mathrm{P}<0.01)$ differences in root and shoot dry weight of salinity, ecotypes, and PGPs, and the interaction among them was also significant $(\mathrm{P}<0.01)$ in both years. Importantly, irrespective of the soil supplementation, the shoot dry weight reduced to higher extent under salinity stress in all ecotypes during both experimental years; however, during 2017 the shoot dry weight of MLE treated plants in KK ecotype was higher under salinity stress as compared to control plants. Data further revealed that AsA followed by MLE, and TU was 


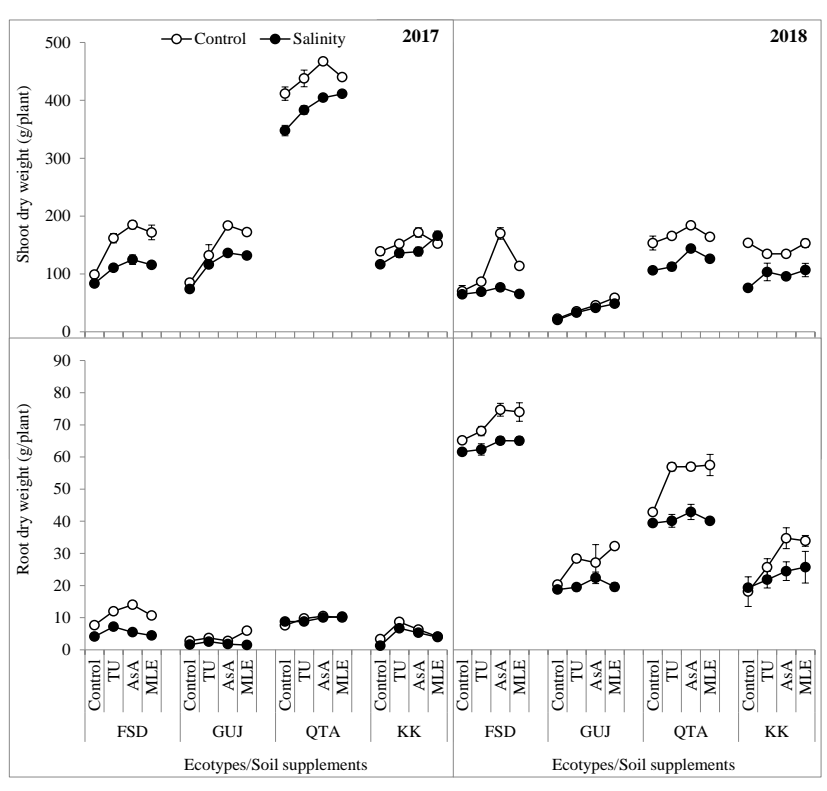

Fig. 1: Plant dry weight (shoot and root) under control and salinity stress conditions. The plants were soil supplemented with different PGPs during 2017 and 2018

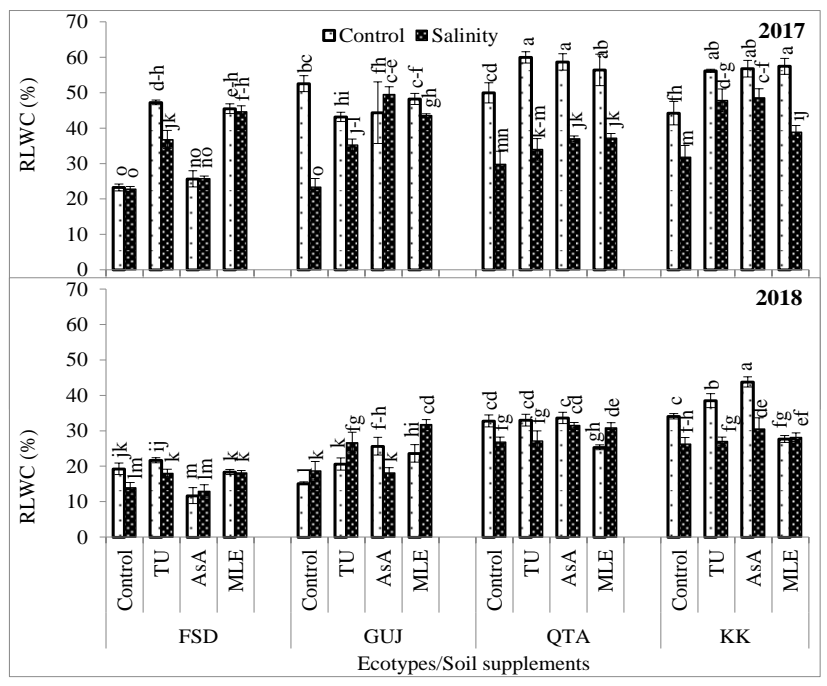

Fig. 2: RWC of milk thistle under control and salinity stress conditions. The plants were soil supplemented with different PGPs during 2017 and 2018. In this and subsequent figures, the data points labeled with alphabets show significant $(\mathrm{P}<0.05)$ overall interaction of all the factors

effective in increasing shoot dry weight during 2017 and 2018 under control and salt stress conditions. Conversely, highest shoot dry weight was recorded in FSD by following QTA, KK, and GUJ under saline and non-saline conditions during 2017, while during 2018 the order of change in this attribute was: FSD > QTA > GUJ and KK. As for QTA ecotype, the shoot dry weight during 2017 was much higher as compared to 2018 (Fig. 1). Data recorded for root dry weight of FSD ecotype followed by QTA, KK, and GUJ was higher under saline and non-saline conditions during 2017 and 2018. Overall, root dry weight increased with the soil supplementation of all the treatments in different ecotypes, and salinity stress caused antagonistic effects in both year studies (Fig. 1).

\section{Relative water content (RWC)}

Results showed that RWC revealed significant $(\mathrm{P}<0.01)$ differences in all ecotypes and different soil supplementations under salt stress, and the interactions of different factors were also significant in both years. Under control conditions during 2017 the order of improvement in RWC of FSD and KK ecotypes was at maximum with the supplementation of TU, while in QTA and GUJ ecotypes the application of TU and MLE showed remarkable differences as compared to other PGPs. Under stress condition, MLE supplementation showed maximum water content in FSD ecotype, whereas AsA supplemented plants had retained higher RWC in other three ecotypes. Considering the ecotypes, QTA ecotype was efficient in retaining higher water contents, while GUJ ecotype was the least efficient under control and salinity stress (Fig. 2). Data recorded during 2018 revealed that under control conditions during 2018 the order of improvement in FSD ecotypes was at its maximum with the supplementation of $\mathrm{TU}$, while in other three ecotypes the application of AsA was more effective as compared to other PGPs. However, under salt stress condition the order of improvement of FSD and GUJ ecotypes was the highest with the supplementation of MLE, while in QTA and KK ecotypes the application of MLE showed remarkable differences. The decreasing order in respect to ecotypes was observed as: FSD $<$ GUJ $<$ QTA $<$ KK (Fig. 2).

\section{Nutrient status}

Nitrate-N: Shoot $\mathrm{NO}_{3}^{-}-\mathrm{N}$ content manifested significant $(\mathrm{P}<0.01)$ differences in ecotypes and salt stress under different soil supplementations and the interaction among them was also highly significant in year 2017, while it was non-significant $(\mathrm{P}>0.05)$ during 2018. Furthermore, shoot and root $\mathrm{NO}_{3}{ }^{-} \mathrm{N}$ content was non-significant $(\mathrm{P}>0.05)$ during 2017, while the interaction between these factors was significant $(\mathrm{P}<0.01)$ during 2018. During 2017 maximum shoot $\mathrm{NO}_{3}{ }^{-} \mathrm{N}$ content was noted in QTA and followed by FSD > KK > GUJ ecotypes (Fig. 3). Soil supplementations with AsA was effective for FSD and QTA ecotypes, while in others the MLE was more effective as compared to other PGPs under control conditions during 2017 and 2018. Under salt stress, AsA supplementation was effective for all ecotypes during 2017, while MLE improved the $\mathrm{NO}_{3}{ }^{-} \mathrm{N}$ content during 2018. Root $\mathrm{NO}_{3}^{-}-\mathrm{N}$ content in control plants of all ecotypes improved maximally with MLE supplementation during 2017. However, during 2018, soil supplementation of AsA was the most effective in increasing $\mathrm{NO}_{3}^{-}-\mathrm{N}$ content in FSD followed by GUJ, KK 


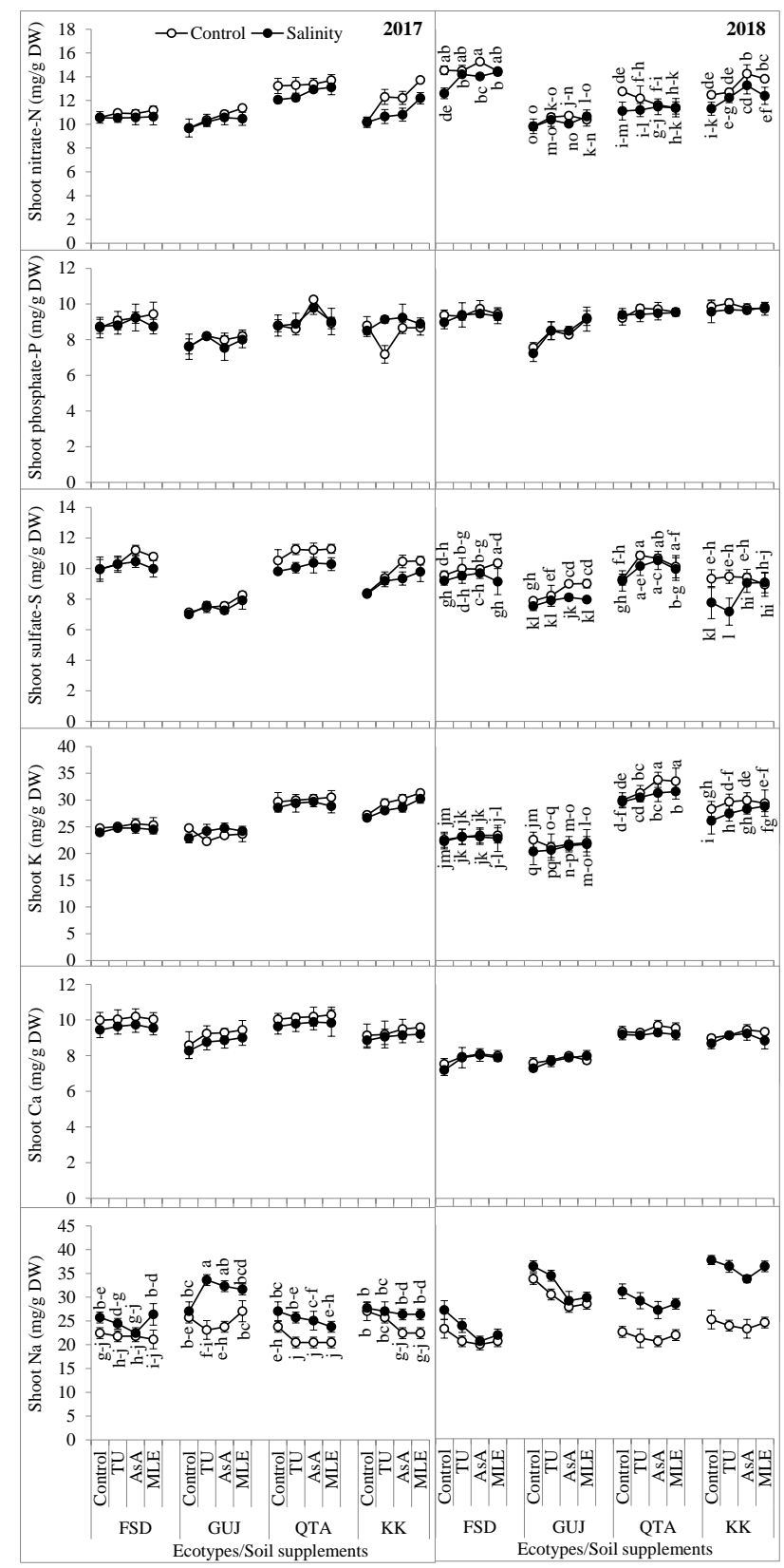

Fig. 3: Changes in the shoot nutrient contents of milk thistle ecotypes under control and salinity stress conditions. The plants were soil supplemented with different PGPs during 2017 and 2018

and QTA ecotypes. Under salt stress, MLE treatment was the most effective in FSD and GUJ ecotypes, and AsA soil supplementation proved better in QTA and KK ecotype as compared to other PGPs. Ecotype from QTA in 2017 and FSD in 2018 displayed higher $\mathrm{NO}_{3}{ }^{-} \mathrm{N}$ content irrespective of the salinity treatment in roots. Nonetheless, salinity stress during both the years tended to decrease the $\mathrm{NO}_{3}{ }^{-} \mathrm{N}$ content in all ecotypes in comparison to their control plants. Furthermore, greater $\mathrm{NO}_{3}{ }^{-} \mathrm{N}$ content was noted in shoot as compared to root, and that also was higher in the year 2017 as compared to 2018 (Fig. 4).

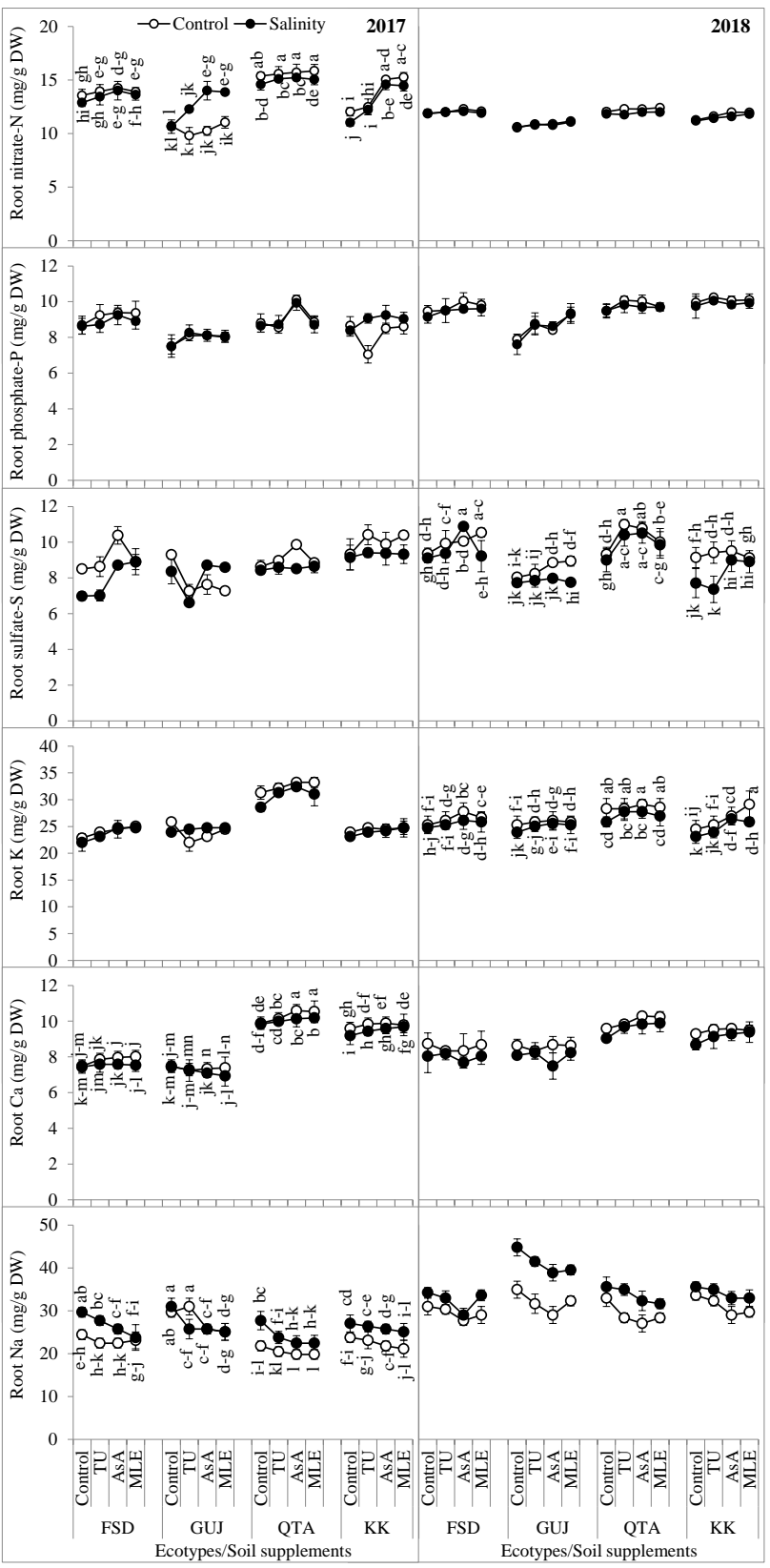

Fig. 4: Changes in the root nutrient contents of milk thistle ecotypes under control and salinity stress conditions. The plants were soil supplemented with different PGPs during 2017 and 2018

Phosphate-P: Results for shoot and root phosphate-P contents displayed non-significant $(\mathrm{P}>0.05)$ differences in ecotypes and salinity under different soil supplementations, and the interaction among these three factors was also nonsignificant $(\mathrm{P}>0.05)$ in 2017 and 2018. In 2017 under control conditions, MLE was more effective in improving this attribute in the shoot of FSD and GUJ ecotypes while in other ecotypes, the effect of AsA was more evident. Under salt stress, the soil supplementation with AsA was more effective for GUJ, while for other ecotypes, MLE was more effective. During 2018 under control conditions, AsA was 
more effective in improving shoot phosphate-P in FSD and QTA ecotype, while MLE and TU, respectively were more effective in GUJ and KK ecotypes (Fig. 3). Data recorded for root $\mathrm{PO}_{4}^{-}-\mathrm{P}$ contents revealed that in 2017, AsA was effective for FSD, QTA and KK ecotypes, while TU was more effective for GUJ as compared to other PGPs under control and stress conditions. Data recorded during 2018, revealed that under control conditions, AsA was effective for FSD ecotype, while MLE and TU showed more effectiveness in GUJ and QTA ecotypes, respectively; while for KK ecotype, TU was more effective. Under salt stress, MLE supplementation was effective for FSD and GUJ ecotypes, while for QTA and KK the effect of TU was greater. Overall, result revealed that salinity during both experiment years tend to decrease the shoot and root $\mathrm{PO}_{4}^{-}-\mathrm{P}$ contents in all ecotypes in comparison to control plants. Nonetheless, QTA ecotype exhibited highest improvement in this attribute with soil supplementation during 2017-2018 under control than under salinity stress (Fig. 4).

Sulfate-S: Data for shoot $\mathrm{SO}_{4}^{-}-\mathrm{S}$ contents in both shoot and root showed significant $(\mathrm{P}<0.01)$ differences in ecotypes and salinity under different soil supplementations and the interaction of these factors was non-sugnificant $(\mathrm{P}>0.05)$ during 2017 but significant $(\mathrm{P}<0.01)$ during 2018. In 2017, considering shoot $\mathrm{SO}_{4}^{-}-\mathrm{S}$ contents of control plants, AsA was more effective for FSD ecotype, and MLE was more supportive for GUJ and KK ecotypes, while in QTA the effect AsA was more evident. A similar trend of increase was found under stress in all ecotypes for improving this attribute. Data recorded during 2018 exhibited that MLE supplementation was effective for FSD and GUJ ecotypes, while TU supplied plants from QTA and KK ecotypes showed higher content of $\mathrm{SO}_{4}^{-} \mathrm{-}$ 的 compared to other PGPs. Importantly, AsA soil supplementation performed better results in saline subjected plants (Fig. 3). Considering root $\mathrm{SO}_{4}^{-}-\mathrm{S}$ in 2017, the AsA was highly effective for FSD and QTA ecotypes, while in GUJ and KK the effect of control and TU supplementation was at its maximum However, under salt stress, AsA increased sulfate-S content more in FSD, while in GUJ no difference was seen with soil supplementations, while in QTA and KK the effect of TU was greater. Data recorded during 2018 exposed that MLE was effective for FSD and GUJ ecotypes, while TU and AsA showed more effectiveness in QTA and KK ecotypes, respectively. However, under stress the effect of AsA was at maximum in all ecotypes. Data recorded for root $\mathrm{SO}_{4}^{-}-\mathrm{S}$ contents revealed that all soil treatments were effective in enhancing root $\mathrm{SO}_{4}^{-}-\mathrm{S}$ contents irrespective of stress and ecotypes differences. On the other hand, highest root $\mathrm{SO}_{4}{ }^{-} \mathrm{S}$ contents was recorded in FSD by following KK, QTA and GUJ under non-saline conditions but under saline was noted as $\mathrm{KK}>\mathrm{FSD}>\mathrm{QTA}>\mathrm{GUJ}$ in 2017. However, in 2018 maximum root $\mathrm{SO}_{4}^{-}-\mathrm{S}$ contents were recorded in QTA by following FSD, KK and GUJ under saline and non-saline conditions (Fig. 4).

K: Results for both shoot and root $\mathrm{K}$ contents showed significant $(\mathrm{P}<0.01)$ differences in ecotypes and salinity under different soil supplementations, and the interaction among them was non-significant $(\mathrm{P}>0.05)$ during 2017 but highly significant $(\mathrm{P}<0.01)$ during 2018. In 2017, the MLE supplementation indicated maximum $\mathrm{K}$ content in the shoot of all ecotypes under control conditions. However, under salt stress the AsA was more effective in all ecotypes except for KK, in which the MLE supply was more effective in improving this attribute. During 2018, AsA supplementation was better in increasing shoot $\mathrm{K}$ content in all ecotypes except for FSD, in which MLE treatment showed maximum increase as compared to other PGPs under control conditions. Centrality, under stress the effect of MLE was more profound for GUJ, QTA and KK ecotypes, while in FSD the AsA treatment was more effective for attaining more K. Considering root part during 2017, the MLE supplied had more $\mathrm{K}$ content as compared to other soil supplements under control conditions. Contrarily under salt stress AsA supplementation was effective for FSD, GUJ, and QTA ecotypes, while MLE increase K content in KK ecotype. Similar results were confirmed during 2018 under control conditions, while under stress AsA treatment was effective for all ecotypes except for QTA ecotype, in which the TU treatment attained superiority over all other treatments. Graphical data showed that during both experimental years (i.e., 2017 and 2018) ecotype QTA had higher $\mathrm{K}$ content followed by $\mathrm{KK}>\mathrm{FSD}>\mathrm{GUJ}$ under control and stressed plants (Fig. 3). Data recorded for root $\mathrm{K}$ content revealed that all soil treatments were rather ineffective in enhancing root $\mathrm{K}$ content irrespective of stress and ecotypes differences during 2017. On the other hand, highest root $\mathrm{K}$ content was recorded in QTA by following FSD, KK, and GUJ under saline and non-saline conditions during 2017. In 2018 maximum root $\mathrm{K}$ was noted in QTA followed by KK, FSD, and GUJ. Overall, result revealed that salinity during both experiment years tend to decrease the root $\mathrm{K}$ content in all ecotypes in comparison to their control plants (Fig. 4).

Ca: Results obtained for shoot Ca content displayed nonsignificant $(\mathrm{P}>0.05)$ differences in ecotypes and salinity under different soil supplementations, and the interaction among these three factors was also non-significant $(\mathrm{P}>0.05)$ in both the years (2017-2018). Furthermore, root Ca content was found statistically significant $(\mathrm{P}<0.01)$ during 2017, while the interaction between the factors observed nonsignificant $(\mathrm{P}>0.05)$ during 2018. Considering shoot part during 2017 maximum Ca content was noted in QTA followed by FSD, KK and GUJ ecotypes, while all soil supplements were effective in all ecotypes in improving shoot Ca. Likewise, AsA supplementation was effective for FSD, while MLE improved Ca in all other ecotypes. While under salt stress AsA was effective for FSD and QTA ecotype, while MLE was more effective for GUJ and KK ecotypes. During 2018 AsA supplementation was effective in all ecotypes as compared to other PGPs under control or salt stress conditions. During 2018, higher Ca content was 
observed in QTA followed by KK, FSD and GUJ under control and saline condition (Fig. 3). As regards root $\mathrm{Ca}$ contents of control plants during 2017, MLE and AsA were equally effective for FSD and QTA ecotype, while AsA did so for KK ecotype. However, under salt stress the MLE was more effective for all ecotypes except for GUJ, in which AsA was more effective. During 2018, under control conditions, MLE was effective for FSD and QTA ecotype, while TU showed more effectiveness in GUJ and KK ecotypes. Ca content in roots was maximally increased during 2017 as compared to 2018. Furthermore, it was observed that salinity during both experiment years tend to decrease the $\mathrm{Ca}$ content in all ecotypes in comparison to their control plants. Furthermore, maximum Ca content was found in shoot as compared to root (Fig. 4).

Na: Results showed that $\mathrm{Na}$ content in both shoot and root had significant $(\mathrm{P}<0.01)$ differences in ecotypes and salinity treatment under different soil supplementations and the interaction among them was also highly significant during 2017, while non-significant ( $>>0.05)$ during 2018. Considering shoot $\mathrm{Na}$ content of control plants, during 2017 the order of increase in shoot Na was: control > TU=MLE > AsA in FSD ecotype, and in GUJ ecotype the effectiveness was: MLE > control > TU > AsA >, while in QTA this order was: control $>\mathrm{TU}=\mathrm{MLE}=\mathrm{AsA}$, and in $\mathrm{KK}$ the order was: control $>\mathrm{TU}>\mathrm{MLE}=\mathrm{AsA}$. Under salinity stress, this order in FSD was: MLE > control > TU > AsA, and in GUJ ecotype the effectiveness was: TU=AsA=MLE > Control, while in QTA this order was: Control > TU > AsA > MLE, and in KK the trend was found as: Control > TU > AsA=MLE. During 2018 the effect of AsA supplementation was more effective in lowering the $\mathrm{Na}$ content in all collected ecotypes irrespective of salinity and control conditions. It was observed that during both experimental years (i.e., 2017 and 2018) ecotype GUJ had higher $\mathrm{Na}$ content followed by KK > QTA > FSD under control and stressed plants (Fig. 3). Data recorded for root $\mathrm{Na}$ content revealed that all soil treatments were highly effective in lowering root $\mathrm{Na}$ content irrespective of stress and ecotypes differences during 2017. On the other hand, highest root $\mathrm{Na}$ content was recorded in GUJ by following KK, FSD and QTA under saline and non-saline conditions during 2017. Under control conditions, the effect of AsA supplementation was more in all ecotypes except for GUJ, in which MLE supplementation was more effective in reducing Na uptake. Under salt stress, the effect of MLE was more profound in lowering $\mathrm{Na}$ content in all ecotypes than the other PGPs. Furthermore, data recorded during 2018 revealed that AsA supplementation was more effective for reducing Na uptake irrespective of salinity treatments. Overall, result revealed that GUJ and KK ecotypes exhibited highest increase in $\mathrm{Na}$ content with salinity stress during 2017-2018 while soil supplementation proved quite effective in reducing both shoot and root $\mathrm{Na}$ content. Overall, higher $\mathrm{Na}$ was present in root part as compared to shoot, and year 2017 was more effective in lowering the Na uptake (Fig. 4).

\section{Principal component analysis (PCA)}

According to the PCA, the components showed $98.24 \%$ variance. Of the components, PC1 (F1) had 70.94\% variance and PC2 (F2) exhibited $27.30 \%$ variance. First link was more positively associated with $\mathrm{Ca}$ and phosphateP. The phosphate-P was closely linked with ecotype from QTA, while K was weekly associated with FSD ecotype. Na contents showed strong association with KK ecotype; while all ions showed no or weak association with GUJ area (Fig. 5).

\section{Correlation}

Among the essential nutrients, shoot nitrate-N, sulfate-S, phosphate-P, $\mathrm{K}$ and $\mathrm{Ca}$ showed positive correlation with SDW during both experimental years under control and stressed conditions. However, the $\mathrm{K}$ and $\mathrm{Ca}$ showed more statistically significant correlation $(\mathrm{P}<0.01)$ as compared to other nutrients. Contrarily, $\mathrm{Na}$ content exhibited a negative correlation with SDW. Besides, root $\mathrm{NO}_{3}^{-}-\mathrm{N}$ indicated significant $(\mathrm{P}<0.01)$ positive correlation with RDW during both experimental years. For $\mathrm{RDW}, \mathrm{PO}_{4}{ }^{3-}-\mathrm{P}$ showed positive correlation during 2017 irrespective to salinity treatment, while non-significant relationship was noted during 2018. The $\mathrm{SO}_{4}{ }^{2-}-\mathrm{S}$ indicated non-significant relationship with RDW during 2017, whereas positive association was seen during 2018. Conversely, $\mathrm{K}$ and $\mathrm{Ca}$ showed non-significant correlation with RDW. Na contents indicated negative correlation with RDW during 2017 and 2018 (Table 2).

\section{Discussion}

There exist substantial phenotypic plasticity in milk thistle for tolerance to salinity and responsiveness of milk thistle of different PGPs both under control and salinity conditions. From these findings, the milk thistle can be ranked as moderately tolerant to salinity based on changes in plant dry weight, but this aspect needs further probe by using a broader range of salinity levels. It has been reported that milk thistle shows the variable response in salinity from different ecological zones of the world (Ghavami and Ramin 2007; Egamberdieva et al. 2013; Hammami et al. 2020), and salinity response ranges from 9-30 dS/m. Salinity is an adverse environmental abiotic factor for plant growth and development as it is known for arresting the cell elongation and expansion (Munns and Tester 2008; Zahra et al. 2018). In this study, in addition to reduction in dry weight (Fig. 1), there was a substantial decline in the RLWC (Fig. 2), which is attributed to ion-toxicity and induced water deficit effects of salinity stress (Munns and Tester 2008).

Like other plants, milk thistly acquires and assimilates nutrients in requisite quantities for better growth and yield (Geneva et al. 2007; Školníková et al. 2019). Some 


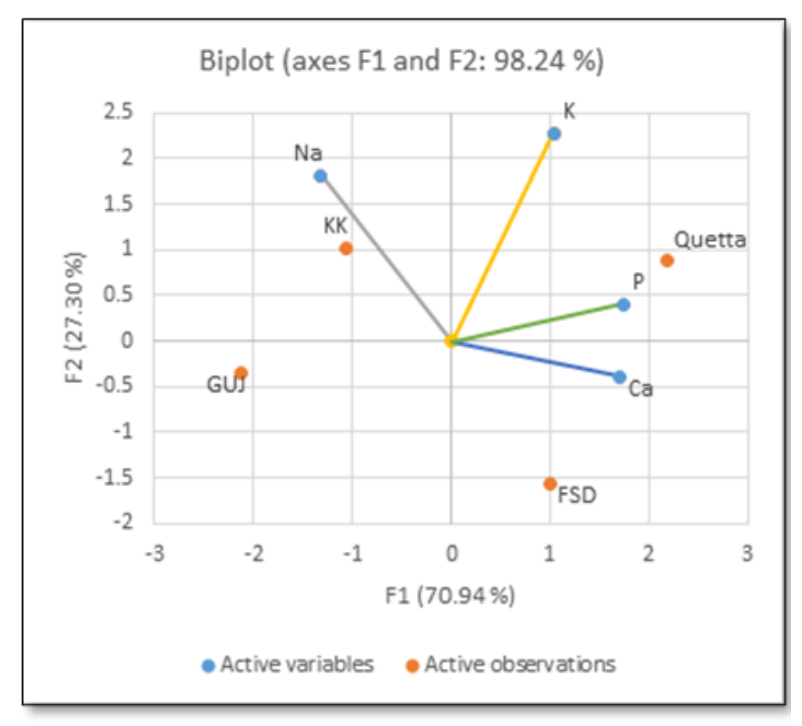

Fig. 5: Principal component analysis of $\mathrm{Na}, \mathrm{K}$, phosphate-P and $\mathrm{Ca}$ in different milk thistle ecotypes

Table 2: Correlation coefficient of shoot and root dry weight with changing nutrient status of milk thistle under salinity during 2017 and 2018

\begin{tabular}{llcccc}
\hline Independent & Dependent & \multicolumn{2}{c}{2017} & \multicolumn{2}{c}{2018} \\
\cline { 3 - 6 } variables & variables & Control & Salinity & Control & Salinity \\
\hline Shoot dry & Shoot nitrate-N & $0.77^{* *}$ & $0.92^{* *}$ & $0.44 \mathrm{~ns}$ & $0.23 \mathrm{~ns}$ \\
weight & Shoot phosphate-P & $0.49 \mathrm{~ns}$ & $0.48 \mathrm{~ns}$ & $0.79^{* *}$ & $0.77^{* *}$ \\
& Shoot sulfate-S & $0.60^{*}$ & $0.48 \mathrm{~ns}$ & $0.72^{* *}$ & $0.65^{* *}$ \\
& Shoot K & $0.60^{*}$ & $0.73^{* *}$ & $0.82^{* *}$ & $0.96^{* *}$ \\
& Shoot Ca & $0.65^{* *}$ & $0.66^{* *}$ & $0.82^{* *}$ & $0.90^{* *}$ \\
& Shoot Na & $-0.55^{*}$ & $-0.31 \mathrm{~ns}$ & $-0.80^{* *}$ & $-0.07 \mathrm{~ns}$ \\
Root dry & Root nitrate-N & $0.62^{* *}$ & $0.66^{* *}$ & $0.76^{* *}$ & $0.77^{* *}$ \\
weight & Root phosphate-P & $0.60^{*}$ & $0.65^{* *}$ & $0.38 \mathrm{~ns}$ & $0.25 \mathrm{~ns}$ \\
& Root sulfate-S & $0.33 \mathrm{~ns}$ & $0.04 \mathrm{~ns}$ & $0.75^{* *}$ & $0.72^{* *}$ \\
& Root K & $0.38 \mathrm{~ns}$ & $0.76^{* *}$ & $0.41 \mathrm{~ns}$ & $0.34 \mathrm{~ns}$ \\
& Root Ca & $0.15 \mathrm{~ns}$ & $0.67^{* *}$ & $0.23 \mathrm{~ns}$ & $-0.12 \mathrm{~ns}$ \\
& Root Na & $-0.61^{*}$ & $-0.47 \mathrm{~ns}$ & $-0.65^{* *}$ & $-0.64 * *$ \\
\hline Significant at: * $<0.05 ; * * \mathrm{P}<0.01, \mathrm{~ns}$ non-significant & &
\end{tabular}

nutrients are both structurally and functionally important (e.g., nitrogen, phosphorous, calcium and sulfur), while others (e.g., $\mathrm{K}$ and $\mathrm{Ca}$ ) are not part of plant structure but are required for physiological processes in soluble form (Taiz et al. 2015). The salinity has an adverse effect on the uptake and assimilation of these essential nutrients by having an ion-specificity effect, which results in reduced tissue nutrient content (Volkov and Beilby 2017). It has been reported that soil supplementation with PGPs has beneficial effects on the root uptake and shoot assimilation of essential nutrients both under saline and non-saline conditions (Abdallah et al. 2020). In this study, the analysis of root and shoot tissues of milk thistle ecotypes for nitrate-N, sulfate-S, phosphate-P, Na, K and $\mathrm{Ca}$ supplemented with of PGPs revealed that salinity reduced the tissue concentration of all the essential nutrients, except $\mathrm{Na}$ concentration, which was increased many folds under salt condition (Fig. 3-4). It is important to indicate that nitrate- $\mathrm{N}$ is among the most vital nutrients absorbed by the roots and assimilates in the number of macromolecules such as proteins, alkaloids and many others nitrogen containing metabolites (Taiz et al. 2015).

Worthily, the ecotypes from QTA and FSD displayed a lesser decline in the shoot and root $\mathrm{Na}$ content under salt stress as compared to those from and GUJ and KK (Fig. 34). This appears to be due to innate ability of these ecotypes to physiologically regulate this toxic ion. As regards changes in the tissue concentration of essential nutrient measured in this study, we found a great deal of variability in the ecotypes to acquire and assimilate different nutrients in shoot and root tissues. Differences in the correlation coefficients of control and salinity stressed plants (Table 2) combined with PCA results (Fig. 5) supported the view that great phenotypic flexibility exists in milk thistle for maintenance of tissue nutrients and eventually salinity tolerance in milk thistle.

\section{Conclusion}

Differences in the four milk thistle ecotypes for growth, leaf water status and contents of analyzed nutrient indicated phenotypic plasticity, in the two years of study under salinity as revealed from correlation coefficient and PCA data. AsA and MLE were more effective PGPs in reducing salt stress effect on the ecotypes. The benefit of soil supplementation with PGPs was not only seen in terms of improved plant biomass but also in the form of higher tissue content of the studied nutrients in curtailing the effect of salinity on milk thistle ecotypes.

\section{Acknowledgments}

This paper is part of $\mathrm{PhD}$ thesis of first author. Thanks to Department of Botany for provision of chemicals and other facilities for performing this work, and ORIC, UAF for providing funds for lab facilities for the current research.

\section{Author Contributions}

NZ and AW conceived the idea; SMA and MA contributed in planning the experiments; NZ analyzed data and prepared initial draft; AW, SMA and MA finalized the paper

\section{References}

Abdallah MMS, TN El Sebai, AAE-M Ramadan, HMS El-Bassiouny (2020). Physiological and biochemical role of proline, trehalose, and compost onenhancing salinity tolerance of quinoa plant. Bull Natl Res Ctr 44; Article 96

Akladious SA (2014). Influence of thiourea application on some physiological and molecular criteria of sunflower (Helianthus annuus L.) plants under conditions of heat stress. Protoplasma 251:625-638

Akram NA, F Shafique, M Ashraf (2017). Ascorbic acid-a potential oxidant scavenger and its role in plant development and abiotic stress tolerance. Front Plant Sci 8; Article 613 
Aliniaeifard S, J Hajilou, SJ Tabatabaei, M Sifi-Kalhor (2016). Effects of ascorbic acid and reduced glutathione on the alleviation of salinity stress in olive plants. Intl J Fruit Sci 16:395-409

Ansari FA, I Ahmad, J Pichtel (2019). Growth stimulation and alleviation of salinity stress to wheat by the biofilm forming Bacillus pumilus strain FAB10. Appl Soil Ecol 143:45-54

Barakat $H$ (2003). Interactive effects of salinity and certain vitamin on gene expression and cell division. Intl J Agric Biol 5:219-225

Benabderrahim MA, M Guiza, M Haddad (2020). Genetic diversity of salt tolerance in tetraploid alfalfa (Medicago sativa L.). Act Physiol Plantarum 42; Article 5

Bhattacharya S (2011). Milk thistle (Silybum marianum L. Gaert.) seeds in health. In: Nuts and Seeds in Health and Disease Prevention, pp:759-766. Academic Press, London

Bhattarai S, D Biswas, YB Fu, B Biligetu (2020). Morphological, physiological, and genetic responses to salt stress in alfalfa: A review. Agronomy 10; Article 5

Egamberdieva D, D Jabborova, N Mamadalieva (2013). Salt tolerant Pseudomonas extremorientalis able to stimulate growth of Silybum marianum under salt stress. Med Aromat Plant Sci Biotechnol 7:7-10

Fageria NK, A Moreira (2011). The role of mineral nutrition on root growth of crop plants. Adv Agron 110:251-331

Feist LJ, DR Parker (2001). Ecotypic variation in selenium accumulation among populations of Stanleya pinnata. New Phytol 149:61-69

Geneva M, G Zehirov, I Stancheva, L Iliev, G Georgiev (2007). Effect of soil fertilizer, foliar fertilizer, and growth regulator application on milk thistle development, seed yield, and silymarin content. Commun Soil Sci Plant Anal 39:17-24

Ghavami N, AA Ramin (2007). Salinity and temperature effects on seed germination of milk thistle. Commun Soil Sci Plant 38:2681-2691

Hammami H, B Saadatian, SAH Hosseini (2020). Geographical variation in seed germination and biochemical response of milk thistle (Silybum marianum) ecotypes exposed to osmotic and salinity stresses. Indust Crops Prod 152; Article 112507

Hoque TS, MS Rana, SA Zahan, I Jahan, MA Abedin (2020). Moringa leaf extract as a bio-stimulant on growth, yield and nutritional improvement in cabbage. Asian J Med Biol Res 6:196-203

Karkanis A, D Bilalis, A Efthimiadou (2011). Cultivation of milk thistle (Silybum marianum L. Gaertn.), a medicinal weed. Indust Crops Prod 34:825-830

Khan S, SMA Basra, I Afzal, A Wahid (2017). Screening of moringa landraces for leaf extract as biostimulant in wheat. Intl J Agric Biol 19:999-1006

Kowalenko CG, LE Lowe (1973). Determination of nitrates in soil extracts Soil Sci Soc Amer Proc 37:660

Lin J, Y Wang, S Sun, C Mu, X. Yan (2017). Effects of arbuscular mycorrhizal fungi on the growth, photosynthesis and photosynthetic pigments of Leymus chinensis seedlings under salt-alkali stress and nitrogen deposition. Sci Total Environ 576:234-241

Lucini L, D Kane, M Pellizzoni, A Ferrari, E Trevisi, G Ruzickova, D Arslan (2016). Phenolic profile and in vitro antioxidant power of different milk thistle [Silybum marianum (L.) Gaertn.] cultivars. Indust Crops Prod 83:11-16

Martinelli T, J Andrzejewska, M Salis, L Sulas (2015). Phenological growth stages of Silybum marianum according to the extended BBCH scale. Ann Appl Biol 166:53-66
Merwad ARM (2018). Using humic substances and foliar spray with Moringa leaf extract to alleviate salinity stress on wheat. In: Sustainability of Agricultural Environment in Egypt: Part II, pp:265-286. Springer, Cham, Switzerland

Munns R (2002). Comparative physiology of salt and water stress. Plant Cell Environ 25:239-250

Munns R, M Tester (2008). Mechanisms of salinity tolerance. Annu Rev Plant Biol 59:651-681

Niamat B, M Naveed, Z Ahmad, M Yaseen, A Ditta, A Mustafa, M Rafique, R Bibi, N Sun, M Xu (2019). Calcium-enriched animal manure alleviates the adverse effects of salt stress on growth, physiology and nutrients homeostasis of Zea mays L. Plants 8; Article 480

Niste M, R Vidican, I Rotar, V Stoian, R Pop, R Miclea (2014). Plant nutrition affected by soil salinity and response of Rhizobium regarding the nutrients accumulation. ProEnvironment 7:71-75

Omidbaigi R, A Nobakht (2001). Nitrogen fertilizer affecting growth, seed yield and active substances of milk thistle (Silybum marianum). Pak J Biol Sci 4:1345-1349

Polash MAS, MA Sakil, M Tahjib-Ul-Arif, MA Hossain (2018). Effect of salinity on osmolytes and RWC of selected rice genotypes. Trop Plant Res 5:227-232

Saddiq MS, S Iqbal, I Afzal, AM Ibrahim, MA Bakhtavar, MB Hafeez, Jahanzaib, MM Maqbool (2019). Mitigation of salinity stress in wheat (Triticum aestivum L.) seedlings through physiological seed enhancements. J Plant Nutr 42:1192-1204

Shahid MA, A Sarkhosh, N Khan, RM Balal, S Ali, L Rossi, C Gómez, N Mattson, W Nasim, F Garcia-Sanchez (2020). Insights into the physiological and biochemical impacts of salt stress on plant growth and development. Agronomy 10; Article 938

Školníková M, P Škarpa, P Ryant (2019). Effect of nitrogen fertilization on yield and quality of milk thistle [Silybum marianum L. (Gaertn.)] achenes. J Elelmentol 24:701-710

Taiz L, E Zeiger, IM Møller, A Murphy (2015). Plant Physiology and Development, $6^{\text {th }}$ edn. Sinauer Associates Inc. Press, Sunderland, Massachusetts, USA

Tendon HLS (1993). Methods of Analysis of Soil, Plants, Water and Fertilizers. Fertilization Development and Consultation Organization, New Delhi, India

Volkov V, MJ Beilby (2017). Editorial: Salinity tolerance in plants: Mechanisms and regulation of ion transport. Front Plant Sci 8 Article 1795

Wahid A, SMA Basra, M Farooq (2017). Thiourea: A molecule with immense biological significance for plants. Intl J Agric Biol 19:911-920

Yoshida S, DA Forno, JH Cock, KA Gomez (1976). Laboratory Manual for Physiological Studies of Rice. International Rice Research Institute (IRRI), Los Banos, The Philippines

Zahra N, A Wahid, K Shaukat, T Rasheed (2020). Role of seed priming and foliar spray of calcium in improving flag leaf growth, grain filling and yield characteristics in wheat (Triticum aestivum) - a field appraisal. Intl J A gric Biol 24:1591-1600

Zahra N, S Mahmood, ZA Raza (2018). Salinity stress on various physiological and biochemical attributes of two distinct maize (Zea mays L.) genotypes. J Plant Nutr 41:1368-1380 